\title{
From Default to Design: Design-Based Assessment for Libraries and Librarianship
}

\author{
Rachel Ivy Clarke \\ Syracuse University, USA
}

\section{Introduction}

There can be no doubt about the recent rise of interest in assessment in librarianship. Popular assessment methods range from quantitative approaches (such as user surveys, usability heuristics, and data and search logs) to qualitative techniques (user interviews, photo elicitation, immersive ethnographies, and more). $M$ any discussions ensue about which of these scientific-based methods is best applicable to the library work at hand, but few have questioned the assumption that scientific methods are the most relevant and applicable assessment methods for librarianship overall.

In the early $20^{\text {th }}$ century, the education of A merican librarians shifted from vocational training situated in work practices to more formalized higher education. The subject's inclusion in the university system at the graduate level shifted focus away from procedural training towards more scientific approaches. ${ }^{1}$ Situating librarianship in the academy helped legitimize it as a profession rather than a vocation, but also emphasized scientific research and publication over practice. ${ }^{2}$ Librarians were increasingly educated in an environment steeped in science, research, and the academy, and in turn, took such scientific conceptualizations with them as they moved into practice. Scholars and researchers in library science emphasized the need for scientific evidence to justify and assess libraries' social and educational value, rather than reliance on experiencebased assumptions and conclusions. ${ }^{3} V$ arious approaches to gathering scientific assessment evidence were drawn upon throughout the $20^{\text {th }}$ century, such as positivistic approaches; ${ }^{4}$ social epistemology; ${ }^{5}$ qualitative inquiry; ${ }^{6}$ hermeneutics; ${ }^{7}$ and evidence-based librarianship. ${ }^{8}$

H owever, new diverse perspectives on librarianship_distinct from science-are emerging. I n recent years, a well-established record of research has demonstrated design as an alternative approach to science. Design is often conceptualized in a limited way in librarianship, focusing on architecture and interior spaces or technological applications like web user experience (UX). ${ }^{9}$ But design is not limited to furniture choices or usability testing. Scholars have identified consistent factors and aspects of design processes across a diverse range of domains that unite design as a unique discipline, distinct from science. Designers from all fieldsfrom architecture to engineering, from fashion to technology-undergo similar processes, revealing a common set of fundamental principles that underlie what Cross calls a "designerly way of knowing." "This is more than just the popular model of the "design thinking" process-it is a fundamentally different approach to knowledge. While science observes and describes the existing world with the goal of replicability and prediction, design creates artifacts intended to solve problems and, ultimately, change the world from its existing state to a preferred state. ${ }^{11}$ Science is about what is, while design is about what could be (or arguably what should be). ${ }^{12}$ Emergent research demonstrates that the field of librarianship is more aligned with these designerly ways of knowing than with science. ${ }^{13}$

This paper argues for the inclusion of design evaluation techniques in library assessment. First, the paper introduces perspectives on assessment from the discipline of design, contrasting them with more traditional forms of scientific assessment. Three common design assessment techniques-rationale, critique, and reflection-are discussed in more detail, with examples to illustrate application and relevance to librarianship. The paper concludes with a discussion of implications for library assessment, including the need for advocacy regarding design approaches in librarianship and how these approaches contribute to furthering the values of librarianship and library services. 
Assessment in design

Unlike science, which aims for predictable, consistent results, design specifically aims for deviations and variations. ${ }^{14}$ Such alternative approaches to know ledge generation naturally will not hold up to scrutiny and critical evaluation based on scientific epistemologies. Because what counts as legitimate knowledge in design is different, then so too must any evaluation methods be different. W hile science relies on specific constructs of evidence, design considers interpretation as a valid form of epistemological evidence. ${ }^{15}$ Scientific evidence may be of assistance to designers by describing existing situations so as to inform decisions. But unlike science, the purpose of design is not to describe the existing world in a factual or objective manner; rather it seeks to change situations and add meaning to them. Therefore, subjective interpretation is a valid form of evidence in design, manifesting through evaluative elements like rationale, expert critique, and reflection.

J ust because design evaluation is not objective in the traditional sense does not mean it is less valid or invalid. What may seem like arbitrary subjectivity to outsiders is actually evaluation based on an extensive repertoire of personal know ledge. ${ }^{16}$ The lack of pre-established and explicitly defined criteria does not automatically mean that an evaluator's subjective opinion comes arbitrarily from thin air. Understanding of values and norms of evaluative criteria have built up over time, from a designer's first critique through all subsequent design evaluations and experiences. It is conformance to-not deviance from-these values that demonstrate and reify an evaluator's authoritative role. Anyone who attempted to arbitrarily assess a design according to their own personal criteria would lose their community status as a reliable and expert evaluator. This idea of community-based affirmations of rigor and value are not limited to design: even the notion of objectivity in scientific epistemologies breaks dow $n$ when viewed from the perspective of social construction. Pinch and Bijker posit that "there is nothing epistemologically special about the nature of scientific knowledge: it is merely one in a whole series of knowledge cultures."17 They reference " primitive" tribes" and other indigenous ways of knowing, ${ }^{18}$ but there is no reason that the epistemology of design is not also a different yet legitimate, knowledge culture. At minimum, design evaluation should consist of a reflective critique by the design's creators. ${ }^{19}$ The following sections describe three examples of evaluative techniques in design-rationale, critique, and reflection, all of which are considered valid, rigorous criteria in any design school or firm, across a variety of design disciplines.

\section{Rationale}

In design, rationale is defined as the "reasons and justifications for choices"20; that is, the reasons why certain choices were made during the process of creating a product or service, and why those choices were selected for enactment and development over others. Unlike more scientific approaches to assessment, which are often conducted after the program or service has been deployed, rationale is a technique that happens after the fact but is also ongoing throughout the design process. Because design (unlike science) does not have any one "right" answer, only better or worse answers, ${ }^{21}$ design relies on the reasoning and rationale behind the choices to understand what led to or what makes a result "better" or "worse."

Rationale-based assessment is gleaned through an examination of the design process: how a design was made, including choices faced, decisions made, and justifications for those decisions. ${ }^{22}$ As an example, I would like to discuss a real project from a library based on a paper I was once assigned to review. The submission discussed the creation of a new database of mural art. Y et the paper was not published, because it did not demonstrate that the database had any sort of effect on patron use. We might say that the paper was not published because it lacked assessment of the project, to know how well it did (or did not) succeed. H owever, just because the project did not utilize traditional scientific criteria for assessment does not mean that the project went unassessed. Although it did not offer findings from a traditional scientific assessment for usage data or feedback from a patron survey, it did discuss reasons for decisions made throughout the creation process. For example, the mural art database enabled users to search for w orks by both artist and geographic location. The intention of this function was to offer multiple access points for connecting with works, and let users both identify locations where art might exist as well as learn more about a work they had encountered in the city. The mural art database project also offered rationale for selecting location as an access point by connecting it to the goals of helping users identify and learn more about a work they encountered while out in the city-without location metadata as an access point, a user who encounters a 
mural at $123 \mathrm{M}$ ain Street would not be able to find information about it in the database. The assessment in this case stems not from the inclusion of location metadata in and of itself, but the explication of the reasons and rationale for its inclusion, and the connection of that rationale to the project's stated goals.

\section{Critique}

Critique is often a scary word, calling to mind memories of harsh, negative criticism, perhaps in front of a large peer group, like reading a poem aloud in a creative writing class only to have the instructor and classmates rip it to shreds. Such experiences are often the extent of knowledge about critique for nondesigners. H ow ever, although some similarities exist (such as classroom and peer settings), w ell-executed design critique is not simply subjective negativity: it systematically articulates a framew ork for evaluation and then compares the work against that framew ork in the form of an ongoing, interactive conversation, ${ }^{23}$ moving beyond the simple "I like it" versus "I don't like it" to the ability to see what users need and how well or poorly any given design may address those needs. ${ }^{24}$

In contrast to science, the underlying purpose of design is not to describe the existing world in a factual or objective manner, but to change situations and add meaning to them. I n contrast to scientific measures of assessment that seek to identify whether something has improved or increased (such as in the case of information literacy testing scores), a novel design artifact may have no meaningful baseline. Therefore, subjective interpretation is a valid form of evidence in design, manifesting through evaluative elements like reflection and expert critique.

Quality critique does not come from thin air -it is a learned skill. A staple of design education, "crit" sessions provide budding designers with direct feedback on the project at hand, prepare them to give and receive constructive feedback, and construct framew orks for evaluation. While assessment may traditionally occur at the end of a project or after a product's deployment, critique sessions should happen throughout the design process, since critique raises questions and potential issues that can and should be addressed before a program or tool or service is deployed. At minimum, design evaluation should consist of a reflective critique by the design's creators. ${ }^{25}$ Unfortunately, for the case of the mural art database, critique only occurred implicitly, in the form of the peer review of the report, not during the project itself. By then it was much too late and much too disconnected from the project.

\section{Reflection}

$M$ any of us are familiar with reflection, or the idea that we look back on a completed project or past situation with serious thought and consideration, such as a reflective essay we might write for English class. Designers, too, look back on projects in a reflective manner, often drawing on such reflection as an evaluation technique. Reflection can help designers learn from their experiences, become more conscious about design activities and choices, and analyze what worked well versus what did not. ${ }^{26}$ This type of afterthe-fact is familiar to most people. Schön calls this idea of designers iteratively making decisions based on previous and potential future decisions "reflection-on-action."27 There is documented evidence of this type of reflection occurring in librarianship, such as in the Valuable I nitiatives in Early Learning that W ork Successfully (VIEW S2) project, which found that purposeful reflection is a key component in the continuous improvement of storytimes intended to increase literacy skills. ${ }^{28}$

But it is arguably designers' engagement in "reflection-in-action," or the ongoing, continual reflection throughout the process of creation that is one of the major aspects distinguishing design from other epistemology. Design is often attributed to innate talent or intuition by people unfamiliar with design epistemologies, both people external to design processes as well as some designers themselves who are ignorant of ways to explain their knowledge. N umerous studies show that designers refer to relying on their personal discretion or intuition when making choices. ${ }^{29}$ Tacit understanding of what is meant by "personal discretion" or "intuition" often contributes to the mystery perceived to surround the design process. But what is commonly attributed to intuition has been dissected and teased out by design scholars and researchers as a type of knowledge based in reflection-in-action. ${ }^{30}$ 
Reflection-in-action can only occur during the process of creating a design artifact, which is why documentation of the design process is critical for design assessment. In the case of the mural database, the reporting authors did offer documentation of the design and development process; however, this was found to be unsatisfactory for the standards of the publication venue, which were based in traditional scientific notions of assessment. Reviewers offered suggestions such as collecting usage statistics and patron feedback surveys to glean the legitimate assessment measures necessary to validate and publish the report of the project. A scientific-based assessment addressing usage (such as a patron survey or database analytics) may have offered know ledge about local adoption and needs. But the discussion and reflection around challenges and decision rationale could offer universally applicable knowledge adaptable by other libraries and related settings, and would therefore be more useful to other professionals and researchers in the field than a survey of local patron use. Such a reflection might include what the researchers learned about library patrons; technological constraints and how they were (or were not) overcome; or how their repertoire was expanded through increased knowledge of art, just to name a few ideas.

\section{Implications}

Rationale, critique, and reflection are all key components of assessment in design. They are also not absent from librarianship. However, when and where they occur in librarianship, they do so implicitly and unsystematically, without the knowledge and substance necessary for rigorous design assessment. This means that librarians are not doing rationale, critique, reflection, and other design methods as well, as rigorously, or as robustly as they could-certainly not at the level designers do.

\section{Advocacy for design approaches in librarianship}

To address this issue, librarians need to advocate for acknowledgement of and capacity for design assessment in librarianship. Librarians need to explicitly embrace these design approaches, embed them in their assessment projects, and learn to do them w ell. To achieve this will require significant shifts in organizational administration and management, publication and communication venues, and professional education.

Library organizations and institutions-and administrative entities who manage them-need to recognize design assessment as a legiti mate and rigorous approach to the evaluation of library tools and services. In addition to mere acknowledgement, management can support design assessment by building in explicit staff time for tasks like critique and reflection, and mandate content such as discussions of rationale in any internal reports. Requiring these design processes as part of any assessment project-and dedicating time and resources to them-demonstrates administrative commitment.

Yet this managerial buy-in will not emerge from thin air. Parallel support from the larger library community is necessary. One major arena for this is dissemination venues like publications and conferences. $M$ any of these venues implicitly establish norms about acceptable approaches and methods through the topics and methods they choose to publish and share with the community. Discussions of rationale and reflection should be mandated in the same way as currently required standard sections like problem statements and literature reviews. Conferences and similar events should include critique sessions, using examples such as the annual video and w ebsite critique sessions offered at conferences like M useums and the W eb as springboards. ${ }^{31}$ Requiring the inclusion of design evaluation methods in publications not only lends credence to these approaches, but ensures that more readers are being exposed to communications about the application of these techniques. If existing venues are not willing to support these aims, new venues that acknowledge the legitimacy of design evaluation need to be created.

Instituting these types of inclusions will require librarians with expertise not only in library-related subjects, but also in design methods and approaches. Contrary to popular belief, design skills are not intuitive-they are learned and honed through explicit education, training, and practice. People unfamiliar with design often assume that it is a simple, linear process, in the same way that people unfamiliar with librarianship often assume the work of librarians is easy, entailing nothing more than reading books all day. W hat librarian has not been asked why anyone would need a graduate degree to do library work? Librarians must not make the 
same assumptions about other fiel ds like design. While the design process may seem like a black box to outsiders, significant education and training has occurred to make the design process appear easy and seamless, in the same way that librarians can make a complex database search look simple to those not versed in Boolean operators and controlled vocabularies. Therefore, to ensure both understanding of and rigor in design as a legitimate assessment practice, librarians need design education. This can be supplied in a variety of means, from local or national professional development sessions to inclusion of design as a fundamental component of formal graduate library education programs like M LIS degrees.

\section{How design approaches support the values of librarianship}

Why is it so important to include design techniques as a legitimate aspect of library assessment? Design assessment methods like rationale, assessment, and critique are what is going to allow us to take the next step beyond use and satisfaction and let us assess whether or not we are aligned with the values we set forth and stand for as a profession. The idea of seeking purposeful change is an inherent characteristic of design, which rests on the idea of problem solving and changing from current states to preferred ones. While design is about solving problems, it offers two differing yet complementary perspectives on problem solving: creating a solution based on what could exist, or creating one that should. ${ }^{32}$ The former identifies possibilities while the latter makes a judgment about the world. All design artifacts carry these value judgmentswhether or not they explicitly admit to doing so. ${ }^{33}$ Therefore, despite librarianship's tradition of offering a neutral and objective standpoint, ${ }^{34}$ values and perspectives about how the world "should" be are embodied in all library artifacts regardless of neutral intentions.

The implicit treatment of design in American librarianship reveals a significant disconnect betw een the creation of library tools and services and the values those tools and services embody and reflect. Librarianship is theoretically guided by values that separate libraries from other commercial providers of information tools and services. For instance, the American Library Association lists 11 core values that ostensibly underlie the profession, including such values as privacy, intellectual freedom, and diversity. ${ }^{35}$ Scientific measures may let us observe and describe the current state of values in librarianship, such as how diverse our staff currently is, or how many challenges to intellectual freedom are received. Quantitative assessment data from a user survey may demonstrate the popularity of a given service, but using values as rationale can demonstrate where that popular service may be failing terms of values like serving diverse and/ or marginalized populations or offering equitable access. Even when traditional methods demonstrate positive assessment, they may be masking issues. But since design is aspirational and normative, driven not by how things are but how they should be, design assessment lets us see where outcomes do (or do not) align with those values, and lets us make changes to support those aspirations, thus purposefully furthering values for which the profession claims to stand.

\section{Conclusion}

$M$ any discussions ensue about which of these scientific-based methods is best applicable to the library work at hand, but few have questioned the assumption that scientific methods are the most relevant and applicable assessment methods for librarianship overall. As the alignment between librarianship and design becomes increasingly evident, librarians need to understand that there is more to design than just a simple process model.

Relying on default traditional scientific methods to assess the outcomes of a design process is like using a ruler to measure a two-liter bottle: it may tell you something, but it may not offer all of the relevant and useful information. Instead, design has its own established evaluation measures, such as rationale, critique, and reflection. It is imperative that, as more and more librarians adopt design approaches, they also adopt assessment methods appropriate to those approaches. $\mathrm{N}$ ot only can design evaluation provide more appropriate evaluation of library tools, programs, and services, but due to its normative nature, it is the only method that allows for the assessment of alignment with core professional values. As people increasingly rely on publicly-available and often commercially-driven information tools and services to meet their information needs, libraries are set apart from these other information providers by a commitment to core values like democracy, diversity, privacy, intellectual freedom, and lifelong learning. Libraries and librarians 
need approaches that highlight and advocate for this difference, and they need methods that help assess the inclusion of these values in all library services.

-Copyright 2019 Rachel I vy Clarke

Rachel I vy Clarke, Assistant Professor, Syracuse U niversity School of I nformation Studies

rclark01@syr.edu

\section{References}

1 C. Edward Carroll, The Professionalization of Education for Librarianship with Special Reference to the Years 1940-1960 (M etuchen, N : Scarecrow Press, 1970).

2. J ohn V. Richardson, J r., The Spirit of I nquiry: The Graduate Library School at Chicago, 1921-1951 (Chicago, IL: American Library Association, 1982).

3. C. C. Williamson, "The Place of Research in Library Service," The Library Quarterly 1, no. 1(1931).

4. Pierce Butler, An I ntroduction to Library Science (Chicago, I L: U niversity of Chicago Press, 1933); Douglas W aples, People and Print: Social Aspects of Reading in the Depression (Chicago, I L: University of Chicago Press, 1938); D ouglas W aples, I nvestigating Library Problems (Chicago, I L: University of Chicago Press, 1939).

5. M argaret Egan and Jesse Shera, "Foundations of a theory of bibliography," The Library Quarterly 22, no. 2 (1952); J esse Shera, "An epistemological foundation for library science," in The F oundations of Education for Librarianship (New York, NY: Becker and H ayes, 1972).

6. Raya Fidel, "Qualitative methods in information retrieval research," Library and I nformation Science Research 15, no. 3 (1993).

7. J ohn M. Budd, Knowledge and Knowing in LIS: A Philosophical Framework (L anham, M D: Scarecrow Press, 2001).

8. Jonathan Eldredge, "Evidence-based Librarianship: An Overview," Bulletin of the M edical Library Association 88, no. 4 (2000); Jonathan Eldredge, "Evidence-based Librarianship: The EBL Process," Library H i Tech 24, no. 3 (2006).

9. Rachel Ivy Clarke, "Designing Disciplinary Identity: An Analysis of the Term 'Design' in Library and Information Science Vocabulary," in ASI S\&T 2015: Proceedings of the 78th ASI S\&T Annual M eeting, N ovember 6-10, St. Louis, M issouri (Silver Spring, M aryland: American Society for I nformation Science and T echnology, 2016), doi: 10.1002/ pra2.2015.145052010074.

10. Nigel Cross, "Design Research: A Disciplined Conversation," Design I ssues 15, no. 2 (1999); Nigel Cross, Design Thinking (Oxford: Berg, 2011).

11. See for example Herbert Simon, The Sciences of the Artificial (Cambridge, M A: M .I .T. Press, 1969); Donald A. Schön, The Reflective Practitioner: H ow Professionals Think in Action ( $N$ ew Y ork, NY: Basic Books, 1983); Nigel Cross, Design Thinking (Oxford, UK: Berg, 2011); H arold G. N elson and Erik Stolterman, The Design Way: Intentional Change in an U npredictable W orld, 2nd ed. (Cambridge, M A: MIT Press, 2012).

12. Jeanne Liedka, "Design Thinking: The Role of Hypothesis Generation and Testing," in M anaging as Designing, ed. R. J . Boland and F. Collopy (Stanford, CA: Stanford U niversity Press, 2004).

13. Rachel I vy Clarke, "It's Not Rocket Library Science: Design Epistemology and American Librarianship," (doctoral dissertation, University of Washington, 2016); Rachel Ivy Clarke, "Toward a Design Epistemology for Librarianship,” The Library Quarterly: I nformation, Community, Policy 88, no. 1(2018): 41-59; Rachel Ivy Clarke, "How We Done It Good: Research Through Design as a Legitimate Methodology for Librarianship," Library and I nformation Science Research 40, no. 4 (2018), https:// doi.org/ 10.1016/j.lisr.2018.09.007; Rachel Ivy Clarke, "Cataloging Research by Design: A Taxonomic Approach to Understanding Research Questions in Cataloging," Cataloging \& Classification Quarterly (2018), https:// doi.org/10.1080/01639374.2018.1491437. 
14. Wolfgang Jonas, "Exploring the swampy ground," in M apping Design Research: Positions and Perspectives (Basel: Birkhäuser, 2012), 12.

15. N elson and Stolterman, The Design Way, 121-122.

16. Adrian Snodgrass and Richard Coyne, Interpretation in Architecture: Design as a W ay of Thinking (L ondon: Routledge, 2006), 123.

17. Trevor J. Pinch and Wiebe E. Bijker, "The Social Construction of Facts and Artefacts: Or How the Sociology of Science and the Sociology of Technology Might Benefit Each Other," Social Studies of Science 14 , no. 3 (1984), 401.

18. Pinch and W iebe, "The Social Construction," 402.

19. Saul Greenberg and Bill Buxton, "Usability Evaluation Considered Harmful (Some of the Time)," in Proceedings of the SIGCHI Conference on Human Factors in Computing Systems (CHI '08), A pril 5-10, Florence, I taly (New York, NY: ACM , 2008) 118, https:// doi.org/10.1145/ 1357054.1357074.

20. John M. Carroll and Mary Beth Rosson, "Design Rationale as Theory," in $\mathrm{HCl}$ M odels, Theories, and Frameworks: Toward a M ultidisciplinary Science, ed. J ohn M. Carroll (San Francisco, CA: M organ Kaufmann, 2003).

21. Horst W. J. Rittel and Melvin M. Webber, "Dilemmas in a general theory of planning," Policy Sciences 4, no. 2 (1973).

22. John Zimmerman, Jodi Forlizzi, and Shelley Evenson, "Research through design as a method for interaction design research in $\mathrm{HCl}$," in Proceedings of the $\mathrm{SI} \mathrm{GCHI}$ Confer ence on $\mathrm{H}$ uman $\mathrm{Factor}$ in Computing Systems (CHI '07), A pril 28-M ay 3, San J ose, California (N ew York, NY: ACM , 2007), 111-120, https:// doi.org/ 10.1145/1240624.1240704.

23. J on K olko, "Endless Nights-learning from design studio critique," Interactions 18, no. 2 (M arch/April 2011), 80-81.

24. Kolko, "Endless Nights."

25. Greenberg and Buxton, "Usability Evaluation."

26. I sabelle Reyman and Dieter K. Hammer, "Structured Reflection for Improving Design Processes," Proceedings of the International Design Conference-Design 2002, Dubrovnik (M ay 14-17, 2002), 888.

27. Schön, The Reflective Practitioner, 66-75.

28. J . Elizabeth M ills, Kathleen Campana, Sean Fullerton, M arin Brouwer, Allyson Carlyle, Cheryl M etoyer, Eliza T. Dresang, "I mpact, advocacy, and professional development: An exploration of storytime assessment in W ashington state," U niversity of W ashington, 2015, http:// views2.ischool.uw.edu.

29. Peter H. Levin, Decision M aking in Urban Design (Garston, UK: Building Research Station, 1966); R. Davies, A Psychological Enquiry into the Origination and I mplementation of I deas: Experience of Unity and Opportunity (M anchester, UK: UM IST, 1985).

30. Cross, Design Thinking.

31 See for example http://mw2016.museumsandtheweb.com/session/video-crit/ and http:// mw2016.museumsandthew eb.com/session/w eb-crit/.

32. J eanne Liedka, "D esign Thinking: The Role of H ypothesis Generation and T esting," in M anaging as Designing, ed. R. J . Boland and F. Collopy (Stanford, CA: Stanford U niversity Press, 2004).

33. L angdon W inner, "Do Artifacts Have Politics?" Daedalus 109, no. 1 (1986).

34. Candice Branum, "The M yth of L ibrary N eutrality," M ay 2014, accessed J une 3, 2016, https://candisebranum.wordpress.com/2014/05/15/the-myth-of-library-neutrality/.

35. American Library Association, "Core Values of Librarianship," June 29, 2004, http://www.ala.org/advocacy/intfreedom/corevalues. 